\title{
Factors Influencing the Use of Evidence-Based Practice among Physiotherapists and Occupational Therapists in Their Clinical Work
}

Sofi Fristedt

School of Health and Welfare, Jönköping University, sofı.fristedt@ju.se

Kristina Areskoug Josefsson

Samrehab, Värnamo Hospital, Värnamo, Jönköping County Council, Sweden, kristina.areskoug.josefsson@rjl.se

Ann-Sofi Kammerlind

Futurum - the Academy for Healthcare, Jönköping County Council, Jönköping, Sweden and Division of Physiotherapy, Department of Medical and Health Sciences, Linköping University, Linköping, Sweden, annsofi.kammerlind@rjl.se

Follow this and additional works at: https://nsuworks.nova.edu/ijahsp

Part of the Occupational Therapy Commons, and the Physiotherapy Commons

\section{Recommended Citation}

Fristedt S, Areskoug Josefsson K, Kammerlind A. Factors Influencing the Use of Evidence-Based Practice among Physiotherapists and Occupational Therapists in Their Clinical Work. The Internet Journal of Allied Health Sciences and Practice. 2016 Jan 01;14(3), Article 7.

This Manuscript is brought to you for free and open access by the College of Health Care Sciences at NSUWorks. It has been accepted for inclusion in Internet Journal of Allied Health Sciences and Practice by an authorized editor of NSUWorks. For more information, please contact nsuworks@nova.edu. 


\title{
Factors Influencing the Use of Evidence-Based Practice among Physiotherapists and Occupational Therapists in Their Clinical Work
}

\begin{abstract}
Background: Evidence-based practice (EBP) is a process through which research is applied in daily clinical practice. Occupational therapists (OTs) and physiotherapists (PTs) are expected to work in line with EBP in order to optimise health care resources. This expectation is too seldom fulfilled. Consequently, research findings may not be implemented in clinical practice in a timely manner, or at all. To remedy this situation, additional knowledge is needed regarding what factors influence the process of EBP among practitioners. The purpose of the present study was to identify factors that influence the use of EBP and the experienced effects of the use of EBP among PTs and OTs in their clinical work. Method: This was a qualitative interview study that consisted of six group interviews involving either OTs or PTs employed by the Jönköping County Council in the South of Sweden. Resulting data were analysed using content analysis. Results: The analysis resulted in the following categories: "definition of evidence and EBP", "sources of evidence", "barriers to acquiring evidence and to using evidence in clinical work", "factors that facilitate the acquisition of evidence and the use of evidence in clinical work", and "personal experiences of using EBP". Basing clinical practice on scientific evidence evoked positive experiences, although an ambivalent view towards acting on clinical experience was evident. Participants reported that time for and increased knowledge about searching for, evaluating, and implementing EBP were needed. Conclusion: Because OTs are more oriented towards professional theories and models, and PTs are more focused on randomised controlled trials of interventions, different strategies appear to be needed to increase EBP in these two professions. Management support was considered vital to the implementation of EBP. However, the personal obligation to work in line with EBP must also be emphasised; the participants apparently underestimate its importance.
\end{abstract}

\section{Author Bio(s)}

- Sofi Fristedt, PhD, OT Reg, is an Assistant Professor in the Department of Rehabilitation, School of Health and Welfare, Jönköping University, Sweden and Researcher at Futurum the Academy for Healthcare, Jönköping Region County Council, Jönköping, Sweden. She is also a Council Certified Specialist in Occupational Therapy.

- Kristina Areskoug Josefsson, PhD, RPT, is an Assistant Professor in the Jönköping Academy for Improvement of Health and Welfare, Jönköping University, Sweden. She is also a Council Certified Specialist in Physiotherapy.

- Ann-Sofi Kammerlind, PhD, PT, is working as a researcher at Futurum - the Academy for Healthcare, Jönköping Region County Council, Jönköping, Sweden. She also teaches at the Department of Medical and Health Sciences, Linköping University, Linköping, Sweden.

\section{Acknowledgements}

The present study was conducted with financial support from Futurum - the Academy for Healthcare, Region Jönköping County Council, Jönköping, Sweden. 


\title{
TIJAHSP \\ The Internet Joutnal of Allied Health Sciences and Practice
}

Dedicated to allied health professional practice and education

Vol. 14 No. 3 ISSN 1540-580X

\section{Factors Influencing the Use of Evidence-Based Practice among Physiotherapists and Occupational Therapists in Their Clinical Work}

\author{
Sofi Fristedt, $\mathrm{PhD}^{1}$ \\ Kristina Areskoug Josefsson, $\mathrm{PhD}^{2}$ \\ Ann-Sofi Kammerlind, $\mathrm{PhD}^{3}$
}

1. Jönköping University

2. Samrehab, Värnamo Hospital

3. Futurum - the Academy for Healthcare, Linköping University

Sweden

\begin{abstract}
Background: Evidence-based practice (EBP) is a process through which research is applied in daily clinical practice. Occupational therapists (OTs) and physiotherapists (PTs) are expected to work in line with EBP in order to optimise health care resources. This expectation is too seldom fulfilled. Consequently, research findings may not be implemented in clinical practice in a timely manner, if at all. To remedy this situation, additional knowledge is needed regarding what factors influence the process of EBP among practitioners. The purpose of the present study was to identify factors that influence the use of EBP and the experienced effects of the use of EBP among PTs and OTs in their clinical work. Method: This was a qualitative interview study that consisted of six group interviews involving either OTs or PTs employed by the Jönköping County Council in the South of Sweden. Resulting data were analysed using content analysis. Results: The analysis resulted in the following categories: "definition of evidence and EBP," "sources of evidence," "barriers to acquiring evidence and to using evidence in clinical work," "factors that facilitate the acquisition of evidence and the use of evidence in clinical work," and "personal experiences of using EBP." Basing clinical practice on scientific evidence evoked positive experiences, although an ambivalent view towards acting on clinical experience was evident. Participants reported that time for and increased knowledge about searching for, evaluating, and implementing EBP were needed. Conclusion: Because OTs are more oriented towards professional theories and models, and PTs are more focused on randomised controlled trials of interventions, different strategies appear to be needed to increase EBP in these two professions. Management support was considered vital to the implementation of EBP. However, the personal obligation to work in line with EBP must also be emphasised; the participants apparently underestimate its importance.
\end{abstract}

\section{BACKGROUND}

Evidence-based medicine (EBM) is defined as "the conscientious, explicit and judicious use of current best evidence in making decisions about the care of individual patients."1 Evidence-based practice (EBP) is a process through which research and clinical experience are synthesised and applied in the clinical context.2,3 Like all health professionals, occupational therapists (OTs) and physiotherapists (PTs) are expected to use EBP to optimise health care resources by using the most effective interventions for their clients. In fact, it may be considered unethical not to offer clients new and appropriate interventions. ${ }^{4}$ Despite this expectation, personal obligation, and ethical aspects, this is not always the case.4,5 Thus, research findings may not be implemented in clinical practice in a timely manner (or at all), causing a knowing-doing gap. In other words, what is known from research is not always implemented in clinical practice.6,7 For example, previous research has shown that although OTs are willing to access new knowledge to guide clinical practice, they do not implement research findings to the fullest extent possible. ${ }^{8}$ The same gap has been observed among PTs. ${ }^{9}$ The existence of this gap may compromise quality in occupational therapy, physiotherapy, and client value. 
The reasons why the EBP obligation is not fully incorporated appear to be multi-faceted. Studies have shown that OTs and PTs lack time to search research databases and are unable to interpret new research in clinical work; they experience these issues as obstacles to the implementation of EBM. ${ }^{10-15}$ Because EBP has become increasingly emphasised over time, not all OTs and PTs may be fully aware of their professional obligation regarding EBP or have access to the means to implement EBP. ${ }^{16}$

Other factors that are important to the implementation of EBP are local cultures and leadership involvement. ${ }^{17}$ Personal factors, including values, beliefs, and work experience, also influence the use and implementation of EBP.12,17 However, aspects that influence the adoption of EBP are often studied with a quantitative design, and more qualitative studies are needed in order to explore the nature of factors that act to bar or facilitate EBP in greater depth.7,18 The present study is subsequent to a research project by the Jönköping County Council. In the previous study, a survey questionnaire was sent to healthcare staff concerning barriers to and factors that facilitate the implementation of EBP. ${ }^{19}$ Overall, the results indicated that the scientific evidence that supports specific healthcare practices is not sufficiently used as a basis for decision-making in daily practice; however, it was not possible to identify explanations for this shortcoming based on the survey-based quantitative design.

Moreover, there were differences between professions; for example, professions with higher education, including OTs and PTs, seemed more prone to (as well as more skilled at) working in line with EBP. ${ }^{19}$ These findings are also mentioned in other research, and supported with respect to OTs and PTs, specifically. ${ }^{20,21}$ These professional differences were simply identified in the surveybased study, and were not further explored in the context of OTs and PTs. ${ }^{21}$ Based on these findings, a broader and more qualitative perspective was considered essential to increase knowledge about facilitators of and barriers to EBP in the clinical practice of occupational therapy and physiotherapy.7,17,18 Such knowledge may be useful to guide the implementation of EBP in these professions, and in others as well. Thus, the current study was initiated with the aim to identify factors that influence the use of EBP and the effects of the use of EBP among PTs and OTs as experienced in their clinical work.

\section{MATERIALS AND METHODS}

\section{Study design}

The study was performed as a descriptive qualitative study in order to capture a comprehensive summary of an event in everyday terms of those events. ${ }^{22}$ Group interviews were chosen for the purpose of identifying the range of ideas that may exist among OTs and PTs related to EBP. ${ }^{23}$ This design was also chosen because of the greater possibility (versus a survey or many other study designs) of identifying aspects that were related to the aim and unforeseen by the researchers but considered important by the participants. ${ }^{23}$

\section{Participants}

Potential informants, employed by the same county council as the three authors, were identified. In order to avoid selection bias, identification was based on professional knowledge relationships; individuals that had a private relationship with any of the authors were not approached. Two of the authors did not do clinical work at the time of the study, and therefore had professional knowledge of the participants rather than a clinical relationship with them. The third author (KAJ) worked as a developmental leader in one unit, with approximately one-half of the participants in groups 4 and 5 (Table 1). Consequently, she did not take part in the interviews involving group 4 or group 5 . 
Table 1. Characteristics of the included sample

\begin{tabular}{|l|l|l|l|l|l|}
\hline $\begin{array}{c}\text { Group } \\
\text { no. }\end{array}$ & Professior & $\begin{array}{c}\text { Number of } \\
\text { participants } \\
\text { (men/women) }\end{array}$ & $\begin{array}{l}\text { Academic degree } \\
\text { (bachelors/ } \\
\text { masters) }\end{array}$ & $\begin{array}{c}\text { No. of years } \\
\text { since } \\
\text { graduation } \\
\text { (Median) }\end{array}$ & \multicolumn{1}{|c|}{$\begin{array}{c}\text { Participants' current work } \\
\text { settings }\end{array}$} \\
\hline 1 & OT & $1 / 2$ & $3 /-$ & $11,12,18(13)$ & $\begin{array}{l}\text { Acute hospital settings, including } \\
\text { stroke and orthopaedics; geriatric } \\
\text { rehabilitation }\end{array}$ \\
\hline 2 & OT & $-/ 4$ & $4 /-$ & $4,8,25,26(16)$ & $\begin{array}{l}\text { Acute hospital settings, including } \\
\text { psychiatrics and orthopaedics; } \\
\text { primary care; rehabilitation } \\
\text { medicine }\end{array}$ \\
\hline 3 & PT & $2 / 3$ & 4 a/1 & $\begin{array}{l}1,3,25,29,42 \\
(25)\end{array}$ & $\begin{array}{l}\text { Acute hospital settings, including } \\
\text { geriatrics, medicine, and } \\
\text { orthopaedics; primary care; } \\
\text { rehabilitation medicine }\end{array}$ \\
\hline 4 & PT & $2 / 3$ & 4 a/1 & $\begin{array}{l}\text { Acute hospital settings, including } \\
(10)\end{array}$ & $\begin{array}{l}\text { geriatrics, medicine, and } \\
\text { orthopaedics; primary care; } \\
\text { rehabilitation medicine }\end{array}$ \\
\hline 5 & OT & -12 & $2 /-$ & $\begin{array}{l}\text { Acute hospital settings, including } \\
\text { medicine; primary care }\end{array}$ \\
\hline 6 & PT & $-/ 2$ & $2 /-$ & $11,15(13)$ & Primary care \\
\hline
\end{tabular}

Note: ${ }^{\text {a }}$ One participant did not hold an academic degree

The intent was to include a varied sample of six participants (regarding gender, years of experience, academic degrees, and work settings) in each group. The groups were separated by profession; OTs and PTs took part in different groups during the interviews to enable professional comparisons. Moreover, this was a strategy to ensure homogeneous groups, as suggested by Krueger. ${ }^{23}$ Although it is possible that some of the participants had also responded to the previous survey, the researchers had no way of knowing who finally responded to the survey. According to Swedish law, no ethical approval was needed to perform the current study. ${ }^{24}$ In agreement with the Declaration of Helsinki, an informational letter was sent by e-mail to potential participants approximately 2 months before the actual day of the interview. The letter discussed the purpose of the present study, and also described how and when data was to be collected. The letter clearly stated that the decision of whether or not to participate would not affect their employment, and that data would be treated and reported with confidentiality in mind so that the identity of participants remained anonymous. They were also able to ask any of the three authors additional questions before providing written informed consent through e-mail. If a potential participant was not able to or did not want to take part in our study, this was accepted without asking for any further explanation. In total, 77 therapists were invited to participate in the study. Fifty-six OTs and PTs declined to participate or did not respond at all to the invitation. Therefore, we were required to send information letters to new potential participants. This process continued until a few days before the day of the interview. As a result of late cancellations, even on the day of the interview, two of the intended interview groups (groups 5 and 6 ) became rather small. However, because the participants in these groups were already on their way to these interview sessions and had reserved time to participate, it was considered most appropriate to conduct these interviews. Otherwise, the information from these individuals might also have been lost, which we considered unethical.

Altogether, nine OTs and twelve PTs chose to take part in this study. All participants were employed by Jönköping County Council in the south of Sweden. The participants worked in three different areas of the county council. Because the distance between these areas was considered too far to mix participants from the different settings, the interviews were held at the hospital that was closest to the majority of participants in a group. The characteristics of the sample are shown in Table 1.

It deserves to be acknowledged that the Swedish education system related to the studied professions has changed over the years. A new system of qualifications including the bachelor degree level was introduced for the OT and PT education programmes in 1993. This system is still valid. As a consequence, OTs and PTs who started their education before 1993 may be registered but lack an academic degree. However, several have complemented their basic training by completing a bachelor's degree. Although it is not a basic requirement for professional practice in Sweden, master's degrees and doctoral degrees are also available within both professions. The Jönköping County Council employs OTs and PTs with all levels of degrees. Apart from one of the authors 
of this paper, no OT or PT with a doctoral degree performs clinical work in the present county council. Therefore, only participants without an academic degree or a bachelor's or master's degree were included (Table 1).

\section{Data collection}

The first author moderated the semi-structured interviews, and the two other authors took turns as the assistant moderator. The moderator had previous experience moderating group interviews. The session was started by the moderator explaining the basic purpose of the study and providing some general guidelines to ensure a positive climate during the course of the interviews. The participants were then allowed to present themselves. All group interviews began with the opening question, "How do you define evidence?"

The following questions were posed when appropriate during the session:

- How do you define EBP?

- Tell us about your knowledge about and experience (positive and negative) of EBP in your work.

- Tell us how you use evidence in your clinical practice.

- How do you find evidence?

- What facilitates and hinders EBP?

- Do you experience any effects of EBP? If so, what...?

Additional questions were added when it was necessary to clarify information provided by the informants. The discussion was continuously summarised by the moderator to avoid misunderstanding. All interviews were digitally recorded. All planned interviews were conducted, and saturation was also reached during the course of interviews. ${ }^{23}$

\section{Data analysis}

Qualitative content analysis was used to analyse the data; this method is recommended when analysing group interviews. 23,25 The interview recordings were transcribed verbatim and read independently by the three authors. Each author open-coded all of the interviews by identifying and making notes in the text that related to the purpose of the study. Common themes and categories were then discussed, and a common coding sheet including 52 subcategories was developed. Each author coded two of the interviews onto this coding sheet, after which each author checked one interview coded by each other author to ensure consistency in coding and categorisation among the authors. Similarities and differences were discussed until consensus was reached with respect to coding and categorisation. The coding of the different interviews was then moved to a common sheet. This was discussed, and similar categories were collapsed based on consensus, resulting in the final number of categories (Table 2). Finally, chosen quotations were translated to English, not word for word but with the intent of preserving the flow and content of the quotations. ${ }^{26}$ They were translated by a professional text reviewer, and then checked and discussed by all authors. As a quality control step, the preliminary findings were finally sent to participants in order to obtain feedback. However, no comments or feedback were returned from the participants. 
Table 2. Summary of Categories and Subcategories

\begin{tabular}{|c|c|}
\hline Category & Subcategory \\
\hline Definition of evidence and EBP & $\begin{array}{l}\text { Insecurity } \\
\text { The value of scientific evidence } \\
\text { The value and status of clinical experience } \\
\text { Conditions in daily clinical practice }\end{array}$ \\
\hline Sources of evidence & $\begin{array}{l}\text { Courses and basic training } \\
\text { Intranet } \\
\text { National guidelines and databases on the internet } \\
\text { Colleagues } \\
\text { Students } \\
\text { Professional networks } \\
\text { Medical library } \\
\text { Research and development coordinator } \\
\text { Clinical visits } \\
\text { Scientific publications } \\
\text { Professional theories and models }\end{array}$ \\
\hline $\begin{array}{l}\text { Barriers to acquiring evidence } \\
\text { and to using evidence in clinical } \\
\text { work }\end{array}$ & $\begin{array}{l}\text { Lack of knowledge about how to search for evidence } \\
\text { Lack of knowledge about how to judge the quality of evidence } \\
\text { Lack of motivation to search for evidence } \\
\text { Prioritising patient care } \\
\text { Lack of time } \\
\text { Lack of evidence and weaknesses of evidence } \\
\text { Conflicting evidence } \\
\text { Patient conditions and motivation } \\
\text { Colleagues and teams } \\
\text { Leadership and organisation } \\
\text { Language barriers } \\
\text { Aversion to change } \\
\text { Evidence/EBP is valued based on clinical experience } \\
\text { Perceived lack of resources } \\
\text { Modifications of clinical guidelines }\end{array}$ \\
\hline $\begin{array}{l}\text { Factors that facilitate the } \\
\text { acquisition of evidence and the } \\
\text { use of evidence in clinical work }\end{array}$ & $\begin{array}{l}\text { Time } \\
\text { Colleagues } \\
\text { Team } \\
\text { Leadership } \\
\text { Knowledge about how to search for evidence } \\
\text { Knowledge about how to judge the quality of evidence } \\
\text { Independent professional role } \\
\text { Willingness to change } \\
\text { Ability to self-generate evidence }\end{array}$ \\
\hline $\begin{array}{l}\text { Personal experiences of using } \\
\text { EBP }\end{array}$ & $\begin{array}{l}\text { Satisfaction } \\
\text { Meaningfulness } \\
\text { Joy } \\
\text { Security } \\
\text { Support for prioritisation }\end{array}$ \\
\hline
\end{tabular}




\section{RESULTS}

Analysis of the interviews resulted in the following categories: "definition of evidence and EBP." "sources of evidence," "barriers to acquiring evidence and to the use of evidence in clinical work," "factors that facilitate acquiring evidence and using it in clinical work," and "personal experiences of using EBP." OTs and PTs usually agreed in general on findings described.

\section{Definition of evidence and EBP}

Participants from both professions seemed insecure about the definition of the concept of evidence. An ambivalent view of the value of scientific results versus the value and status of clinical experience (both personal and more generally accepted experience) was also common among OTs and PTs as illustrated by the following conversation between OTs (fictive names):

Mary - For me, evidence is working according to the theories and models that exist, that you learn about in your basic training, so that you update that knowledge, but experience can also be a form of evidence.

John - Yes, yes.

Mary - Even though you're not supposed to say it, that's still the way it is.

Liz - That's the way we work very much.

$\ldots$

John - I felt a little ... that it would be a little finer and more valuable to work based on evidence than clinical experience.

Nevertheless, both OTs and PTs often had to rely on clinical experience as confirmed by one OT saying: "If you think about geriatric rehabilitation, it's very broad. And how much research has there been in that? In other words, if you think about specific physical difficulties, much [assessment and intervention] is based on clinical experience."

Weighing the scientific evidence and clinical experience was discussed, as were conditions in daily clinical practice that must be considered. Both OTs and PTs considered daily clinical practice to include several aspects, including the abilities and preferences of both the therapist and the individual patient, as well as the requisites of the organisational environment: "It [the intervention] has to suit the individual and the context in which you are. It has to be possible to carry it out (PT)."

\section{Sources of evidence}

Both PTs and OTs usually tended to rely on what was taught in courses and their basic training as scientific evidence: "I do what I learned in my basic training and hope it's right (OT)." Members of both professions also saw academic courses as a way to acquire additional evidence after basic training: "I myself feel it's very important to continue to educate myself. And I very much like to take courses through University. Because then you know that it's built on evidence (OT)."

Participants from both professions used guidelines and other documents on the County Council intranet as well as national guidelines and databases such as Cochrane and PubMed on the Internet. Colleagues were also mentioned as a source of evidence. This was especially true for experienced colleagues with expertise in an area; however, newly trained colleagues with fresh knowledge and new approaches were also appreciated as sources of evidence. Several examples were mentioned in which students in clinical education had shared new knowledge and assisted with evidence searches. Some participated in or knew about regional or international professional networks, and they felt that networking was very rewarding for knowledge exchange and should be utilised more.

Other sources of evidence mentioned by both OTs and PTs were libraries, research and development coordinators, and visits to colleagues at other clinics. The County Council's medical libraries were considered an important resource offering good service, but those working at the hospitals at which the libraries were located most commonly mentioned their use.

Some therapists said that it was possible to identify evidence through weekly and daily newspapers, but that they then had to look up the original sources. PTs preferred randomised controlled studies, while OTs referred more often to professional theories and models. This may be explained by difficulties in searching for and finding scientific results, as one OT reflected:

I think about many of the interventions that we do as occupational therapists. There isn't so much evidence to find about that. It's like what's tradition, what's always been done, and then you start to search for evidence about that, and you don't find anything good.

\section{Barriers to acquiring evidence and to using evidence in clinical work}

Although both OTs and PTs used a large variety of sources to find evidence, they sometimes lacked skill in critical appraisal of the sources: "But, like I said, I don't read enough articles to be able to have a method for examining an article. I don't have it [such

(c) The Internet Journal of Allied Health Sciences and Practice, 2016 
method] (OT)." Individuals in both professions described a lack of knowledge of the easiest and best way to find evidence: "Even if you would get a little time one day, you've forgotten a lot. And then it's very time- and energy-consuming to start with the search process (PT)."

There was a lack of knowledge regarding how to judge the quality of both scientific publications and the overall status of evidence in an area. Some individuals were confident in their skills when searching for and validating evidence, while others were more uncertain of their abilities. OTs and PTs were aware of some existing tools that could be useful when judging quality of evidence; however, knowledge of how to use these tools varied. One PT reflected upon this dilemma:

The results of studies like that, as far as I can understand, are pretty much in agreement that all methods that are studied have an effect as compared with no treatment at all. But it's hard to actually say that there is evidence that one method is better than another.

Both OTs and PTs described a lack of motivation to search for evidence. Belief in the high value of their basic education was sometimes used to explain why they did not search for new evidence; "...it's hard to motivate yourself to do it. ...you have a basic education that you've gone through, and anyway, it is based on knowledge, so it has to count for something (OT)."

Some participants cited prioritising patient care as an explanation for why new evidence was not sought. This opinion existed in both professions: "I give first priority to patients. There's more and more to do all the time, so it's hard to get the time to make searches (OT)." Lack of time was also a barrier to seeking evidence for OTs/PTs: "Searching for articles in the databases... before we had time that was allotted to do it...that disappeared a couple of years ago. There was a lot of discussion about that [decision]" (PT). Moreover, some also described time as a barrier to the implementation and use of evidence in clinical occupational therapy and physiotherapy practice. One PT said:

There are many studies and research that say that stroke patients get too little rehabilitation, hip fracture patients get too little rehabilitation, but nothing is written about where to get that rehabilitation. We don't have the time; we have such short length of stays [sic].

Participants from both professions described both a lack of evidence and weaknesses in evidence as barriers to EBP. As described by one PT:

Then there's no guarantee that either colleagues, basic training, or the literature have a good answer. And then you have to go a little on a feeling that you get. You have to try to put together all the pieces of the puzzle and maybe get half a picture, but even so, use that.

In the OTs/PTs' opinion, lack of evidence mainly concerned treatment methods and the therapeutic approach, despite their importance to both professions. One OT reflected:

I perform a lot of conversations in my job, I mean both conversations about occupational therapy issues and more supportive conversations, and I sometimes think that it's hard to feel that I have evidence that guide [sic] me [in supportive conversations] since I don't have that education. I know about occupational therapy interventions and I feel like I have scientific proof for that, but supportive conversations I have like... they weren't a part of my education and I haven't gotten more education about it after.

Although qualitative studies were not valued as highly as other scientific studies, they could still have an impact on the therapeutic approach. This view seemed to be more common among PTs, as illustrated by one PT saying:

I think it's very interesting to read qualitative studies in my area, but they don't give the kind of knowledge so that l'd change my treatment methods. But they give knowledge about how I may act... How much information I need to give, how I need to think so that my patient catches up, and more qualitative aspects of that kind.

Scientific results were sometimes considered contradictory, which could make it difficult for OTs/PTs to know what to trust: "Then there are also too many times when you read maybe seven articles that all say different things (PT)." If the patient's condition or motivation does not match what the evidence says, it may also be difficult to implement evidence-based interventions. Several discussions in the interviews concerned how to motivate patients, rather than concerning EBP alone.

(c) The Internet Journal of Allied Health Sciences and Practice, 2016 
A conversation that took place in one of the OT groups illustrated how different cultural perspectives between patients and OTs/PTs sometimes functioned as a barrier to EBP:

Mary: It's like we haven't gotten the opportunity to get close to and do what we actually ordinarily do: early assessment and early mobilisation. And he [the relative of a client] has, like, taken over and almost denied us.

...

Liz: But you feel when you have patients that are from another country that it's completely different. It has a lot to do with lying in bed and resting until you're healthy. And also that relatives come and take over in a completely different way than we Swedes do.

OTs and PTs sometimes had to act as salespeople to motivate the patient, and occasionally offered interventions that were not evidence-based in order to get the patient to cooperate in evidence-based interventions. One PT provided this example: "If Charles won't get better with passive treatment in the long run, but needs a more active coping strategy, it can sometimes be helpful with passive treatments to get him along in the active treatment later on."

Different approaches, both between colleagues in the same profession and among different professions within the team, could also become barriers to EBP: "The physician...steers things in another direction. And then I can't...hold a discussion like that in the face of the patient (PT)." A lack of interest and low prioritisation of EBP from leaders and the organisation were additional barriers within OT and PT practice; "...there's no one who demands that I work in an evidence-based way. No one has said that (PT)."

Ongoing systemic changes towards more non-public alternatives and competitive care provision were believed to complicate cooperative efforts to implement EBP. An OT said, "I have to compete with the other primary care units. I have to give the best care, best and most effectively. I must absolutely not cooperate with private parties...network meetings aren't actually allowed to take place".

When reading research reports, language can be a barrier for participants from both professions, as illustrated by a PT:

I feel that the language is somewhat a barrier, all the research is in English, even if I'm not so bad at it. But it makes it a little hard. It's not like you can just skim it through, and get a quick idea about it. You have to give it time.

OTs and PTs each described an aversion to change, both in themselves and in others. In both professions, the choice of including new evidence in clinical practice was based on clinical experience: "I probably work much more from my own experiences than because something says that it should be that way (OT)." Old habits also mattered for both PTs and OTs. With a bit of irony, one of the PTs stated: "Here we do what we've always done."

A perceived lack of resources can hinder adherence to EBP when it comes to, for example, type or intensity of intervention. Furthermore, resources are not always distributed to fit the requirements of the evidence-based national guidelines, according to participants from both professions. An OT group had the following discussion:

Beth - We talked a little bit about the stroke guidelines. They've shown very high evidence in terms of home rehabilitation... That's one national guideline.

Jane - It's also about resources.

Beth - So then the social welfare board says that they [the patients] should go home as soon as possible. They shouldn't stay on at the rehabilitation medicine clinic, because they have to go home. Then the ones that decide have to re-route the resources.

The evidence must be adapted to each patient and to what is feasible, and sometimes only parts of a clinical guideline can be used in both OT and PT. One PT reflected: "lt's great that research is done. But what do things look like in reality? But if you can work according to it [research], it's really fun."

\section{Factors that facilitate the acquisition of evidence and its use in clinical work}

A willingness to embrace change was considered a prerequisite for EBP. Factors that facilitated EBP included getting time or giving yourself the time to search for evidence during working hours, even if this involved some struggle for both PTs and OTs: "But actually, we are required to work evidence-based. So actually, you should take time each week. But the question is what you shouldn't bother with instead (PT)." 
The support of colleagues, team members, and leaders in prioritising searches for evidence and the implementation of new evidence-based interventions in clinical practice was a facilitating factor, according to OTs and PTs, as illustrated by this reflection by a PT:

It depends on how you make time and room. At my workplace, there are two of us who are physiotherapists, and we've reserved one hour a week to just search for articles that we read and discuss what we think. It's a good way."

Knowledge about how to search for and grade evidence facilitated the ability to look for, prioritise, and manage to use new knowledge. OTs/PTs also considered training in how to search for evidence a facilitating factor: "If you're used to searching, then you probably do it easier (OT)." It was also considered a facilitating factor if one's colleagues searched for evidence and shared their knowledge.

The independent role of OTs/PTs presents opportunities to choose evidence-based actions. One OT said: "I feel that we're pretty free to choose what interventions we offer the patients."

\section{Experiences of using EBP}

Some participants had experience assisting with scientific studies, and thus saw the potential to generate their own evidence. EBP provided a feeling of knowing what to do that was experienced as extremely important. Moreover, using EBP was associated with feelings of satisfaction, meaningfulness, joy, and security. Both OTs and PTs perceived support for prioritisation as an effect of evidence-based rehabilitation. As one OT put it:

If I do something that really is evidence-based, it feels good. It's fun, and I probably prefer to choose those interventions. Because it has a lot to do with feeling that it makes you feel good."

\section{DISCUSSION}

The present study aimed to identify identify factors that influence the use of EBP and effects of EBP use, as experienced by PTs and OTs in daily clinical practice. Few differences were observed between OTs and PTs regarding factors that influence EBP. The major difference seemed to be that OTs more often referred to professional practice models, while PTs more often referred to randomised controlled trials (RCTs) of interventions as support for EBP. Although theories may well be used to guide practice, they are generally not considered a source of scientific evidence. ${ }^{27}$ Moreover, OTs seemed more willing than PTs to use findings from qualitative studies to guide practice. Other types of studies than RCTs, such as case studies and qualitative analyses, may well be useful to inspire and guide practice. ${ }^{27}$ Different types of sources have different advantages and shortcomings, which in turn may affect the way different professionals work in the context of daily clinical practice.

The use of inappropriate knowledge sources as the foundation for decisions in clinical work may lead to suboptimal or ineffective rehabilitation. ${ }^{28}$ Relying solely on RCTs carries the risk that unforeseen aspects, including but not limited to a client's subjective perspectives, will be neglected. On the other hand, qualitative studies obviously do not provide information about the effectiveness of different interventions. These professional differences between OTs and PTs point to the fact that different strategies may be needed to increase the use of different and complementary sources to support EBP in these two professions. This is important information to guide the education of future therapists and the management of clinical quality improvement.

OTs and PTs appeared to share opinions regarding the other factors identified in the present study. The participants' understanding and use of EBP depends on a practical component and a knowledge component, which is in agreement with earlier research. ${ }^{29}$ The practical component consists of time; organisational and individual factors; and the necessary resources to search for, find, assess, and interpret evidence. ${ }^{29}$ The knowledge component relates to understanding research concepts, and having knowledge about how to search for and validate evidence. ${ }^{29}$ Those components are evident in our findings, as both barriers and facilitating factors. During the interviews, barriers and facilitating factors were often intertwined, which enriched the findings. The same aspect (e.g., time) could be both a barrier and a facilitating factor.

Time is a practical barrier. Our research findings are in line with earlier research, showing that rehabilitation staff considers a lack of time to be a great barrier to implementing new research in their clinical practice.10,11,14,15 However, time also likely affects attitudes and the organisation of priorities. For some participants, working in line with EBP seemed to be more important; consequently, more time and effort seemed to be devoted to the process of searching for and validating scientific evidence. Other participants relied more on their basic training and concluded that they worked more or less as they always had. It seems reasonable to assume that this latter group of OTs/PTs were less likely to devote time to the EBP process than former group. Moreover, they are potentially

(C) The Internet Journal of Allied Health Sciences and Practice, 2016 
less aware of their personal obligation to work in line with EBP. Although more time is needed in general, individual strategies to increase the implementation of EBP and the awareness of professional obligation is probably needed to successfully address these differences in attitude. Nevertheless, according to our participants, time shortage was also an increasing problem partly as a result of organisational changes. For example, OTs/PTs increasingly worked in multi-professional teams without close access to colleagues from the same profession. As they were directed by management not to collaborate through networking, the process of searching for and implementing EBP that was relevant to their own professional practice became an even lonelier pursuit. When designing processes and changing organisations, it is thus important to acknowledge and enable professional development, as well as to facilitate collaboration and provide support for the implementation of EBP.

Both management and organisational factors, such as how clinical practice is designed and how resources are distributed, are practical components that can affect the use of EBP. 10,29,31,32 These factors must be explored in greater depth, especially because management and clinical therapists often value the challenge of implementing EBP differently. ${ }^{27}$ In our study, lack of support from leaders and difficulty performing some types of rehabilitation interventions owing to the clinical setting were described as barriers for EBP. Yet, although managerial support is clearly important, it must not be overestimated. In fact, some of our study participants did not even consider it necessary to work in line with EBP, arguing that nobody had said that they should. This is surprising, because the Swedish law states that EBP is a personal obligation for registered OTs and PTs. 5,33,34 Thus, knowledge about this personal responsibility must be articulated more strongly and in greater detail by (for example) professional organisations and authorities. Moreover, the general trend in health care suggests a higher demand for EBP, supported by health economics. 35,36 OTs and PTs must be aware of this trend and implement EBP to secure the value of their professions. Because evidence to support a therapeutic approach and treatment methods has been acknowledged as especially limited, these areas probably deserve special attention. However, this limitation must be explored in future research.

Language is a yet another practical component that should be considered when implementing EBP. The language barrier has been mentioned in earlier research. ${ }^{33,37,38}$ To facilitate international implementation, almost all research is written in English, which might lessen the availability of the research to Swedish health care professionals, for example. Consequently, guidelines should be written in country's official language. The present study showed that OTs and PTs lack the necessary skills to search for and validate scientific evidence, and therefore require several avenues of support regarding the knowledge component of EBP. A recent systematic review suggests that educational interventions may support the implementation of evidence, but that education alone is not sufficient to change the behaviour of allied health professionals. 30,39 According to that same study, other factors relevant to a successful implementation process remain to be identified. ${ }^{30}$ Time (in combination with attitudes, as previously discussed) may be one such factor. Nevertheless, it seems reasonable to assume that knowledge may facilitate the process of searching for and validating evidence that must be implemented. The perceived lack of evidence may actually originate from limited knowledge about how to search for and validate scientific evidence. In fact, both OTs and PTs expressed a need for increased knowledge regarding the easiest way to find new and useful evidence concerning their professions, such as the use of "national guidelines" or reviews instead of a personal search for individual articles in PubMed. Such knowledge and strategies may make the process more effective and could save precious time.

Competence at finding the most appropriate therapy interventions should also be explored in greater depth, considering the type of evidence that therapists look for. In our study, PTs and OTs were more likely to search for evidence for diagnosis-specific treatment methods than for evidence concerning more general (but important) strategies or approaches, such as therapeutic issues or coaching. Thus, important knowledge supporting the therapeutic and coaching roles of both professions may be neglected. Judging the quality of new knowledge and new research is another part of the knowledge component. Peer knowledge is important and highly valued among rehabilitation staff, and our results show appreciation of new knowledge both from newly educated staff and from colleagues who had a wealth of work experience, specialisation regarding certain client groups, or more academic education. 36,40 Unfortunately, our participants did not discuss how or whether they critically viewed this peer knowledge in the same way that they would have graded research findings.

Therapists in our study also mentioned that "they work as they always have," a working model that has been termed "practice style trait.".27 This model lessens the willingness to change and to adopt EBP, and also affects how new research is assessed. ${ }^{41}$ The therapists also showed signs of confirmation bias; they seemed more prone to adopt evidence that confirmed their existing beliefs. ${ }^{42}$ Based on our findings, it is essential to increase knowledge about how to assess research and peer experienced knowledge and how to enhance critical thinking in order to optimise rehabilitation and implement EBP.

While communicating about the effects of using EBP, the participants described their personal feelings. It is remarkable that the effects for patients were not explicitly mentioned in relation to these positive, personal feelings, particularly because patient involvement is considered increasingly important in health care and rehabilitation. However, positive feelings and positive earlier

(C) The Internet Journal of Allied Health Sciences and Practice, 2016 
experiences regarding EBP increase the use of EBP and are important for the implementation and change of work routines. ${ }^{29}$ This interaction between individual feelings and improved use of EBP should be employed in EBP implementation activities to increase the potential for successful results.

\section{Methodological considerations}

Group interviews were useful for identifying a wide range of perspectives related to the purpose of the present study. Saturation was reached during the course of the interview, and all six interview sessions contributed to this saturation. Regarding the selection of the participants, a varied sample was sought with respect to the level of academic education, because of its importance for using and understanding EBP. ${ }^{29}$ There is a potential risk of selection bias when researchers themselves choose participants. However, because several individuals $(n=56)$ declined to participate, the sample process in this study had to continue until close to the interview occasion, which reduced the risk of selection bias. It is possible that a sample of participants with higher academic degrees would have affected the results. For example, OTs/PTs with doctoral degrees would likely have been more skilled at critical thinking, as well as the process of searching for and validating scientific evidence. However, there were no OTs or PTs with doctoral degrees working close to clinical practice at the time of the study. Although the participants represent themselves rather than the general population, they share education levels with the vast majority of clinically practising OTs/PTs. Owing to the design of the present study, these results are all transferable to other contexts involving OTs and PTs in primary care and in somatic hospital work settings.

\section{CONCLUSION}

Using EBP, and especially practices based on scientific evidence, was associated with positive experiences by OTs and PTs, even if they had ambivalent views of the value and status of acting on clinical experience as an aspect of EBP. Time for and increased knowledge about searching, evaluating, and implementing EBP were needed, according to participants from both professions. Increased knowledge was also expected to have the additional facilitating effect of saving time in the EBP process. Individual aspects (e.g., attitudes) must also be addressed when working to implement EBP among OTs and PTs. Because OTs were more oriented towards professional theories and models, and PTs were more focused on RCTs of physiotherapy interventions, different strategies may be needed to increase the use of EBP in these two professions. Moreover, although management support is vital to implement EBP, the personal obligation to do so also must be emphasised, particularly because the study participants appeared to underestimate it.

\section{REFERENCES}

1. Sackett DL, Rosenberg WM, Gray JA, Haynes RB, Richardson WS. Evidence based medicine: what it is and what it isn't. British Medical Journal. 1996;312:71-2. [PMID: 8555924]

2. Glegg SM, Holsti L. Measures of knowledge and skills for evidence-based practice: a systematic review. Canadian Journal of Occupational Therapy 2010; 77:219-32. [PMID: 21090063]

3. Bennett S, Bennett J. The process of evidence-based practice in occupational therapy: Informing clinical decisions. Australian Occupational Therapy Journal. 2000;47:171-80.

4. Kumar S, Grimmer-Somers K, Hughes B. The ethics of evidence implementation in health care. Physiotherapy Research International. 2010;15:96-102. [PMID: 20564759]

5. Swedish National Board of Health and Welfare. Management System for Systematic Quality Work. Swedish National Board of Health and Welfare, Stockholm; 2011

6. Rycroft-Malone J. From knowing to doing - from the academy to practice. International Journal of Health Policy and Management. 2015;2:45-6. [PMID: 24596897]

7. Cochrane LJ, Olson CA, Murray S, Dupuis M, Tooman T, et al. Gaps between knowing and doing: understanding and assessing the barriers to optimal health care. Journal of Continuing Education in the Health Professionals. 2007;27:94-102. [PMID: 17576625]

8. Lyons C, Brown T, Tseng MH, Casey J, McDonald R. Evidence-based practice and research utilisation: Perceived research knowledge, attitudes, practices and barriers among Australian paediatric occupational therapists. Australian Occupational Therapy Journal. 2011;58:178-86.

9. Richardson B, Lindquist I. Metasynthesis of qualitative inquiry research studies in physiotherapy. Physiotherapy Research International. 2010;15:111-7. [PMID: 20183861]

10. da Silva TM, Costa Lda C, Garcia AN, Costa LO. What do physical therapists think about evidence-based practice? A systematic review. Manual Therapy. 2015;20:388-401. [PMID: 25458142]

11. Grimmer-Somers K, Lekkas P, Nyland L, Young A, Kumar S. Perspectives on research evidence and clinical practice: a survey of Australian physiotherapists. Physiotherapy Research International. 2007;2:147-61.

12. Salbach N, Guilcher S, Jaglal S, Davis D. Determinants of research use in clinical decision making among physical therapists providing services post-stroke: a cross-sectional study. Implementation Science. 2010;5:77 [PMID: 20946678]

(C) The Internet Journal of Allied Health Sciences and Practice, 2016 
13. Tomlin G, Borgetto B. Research Pyramid: a new evidence-based practice model for occupational therapy. American Journal of Occupational Therapy. 2011;65:189-96. [PMID: 21476366]

14. Iles R, Davidson M. Evidence based practice: a survey of physiotherapists' current practice. Physiotherapy Research International. 2006;11:93-103. [PMID: 16808090]

15. Jette D, Bacon K, Batty C, Carlson M, Ferland A, et al. Evidence-based practice: beliefs, attitudes, knowledge, and behaviors of physical therapists. Physical Therapy 2003;83(9):786-805. [PMID: 12940766]

16. Laver Fawcett A. Principles of Assessment and Outcome Measurement for Occupational Therapists and Physiotherapists: Theory, Skills and Application. Chichester: John Wiley; 2007.

17. Kristensen HK, Persson D, Nygren C, Boll M, Matzen P. Evaluation of evidence within occupational therapy in stroke rehabilitation. Scandinavian Journal of Occupational Therapy. 2010;18:11-25. [PMID: 20331393]

18. Graham F, Robertson L, Anderson J. New Zealand occupational therapists' view on evidence-based practice: A replicated survey of attitudes, confidence and behaviours. Australian Occupational Therapy Journal. 2013;50(2):120-8. [PMID: 23551005]

19. Areskoug Josefsson K, Kammerlind AS, Sund-Levander M. Evidence-based practice in a multiprofessional context. International Journal of Evidence Based Healthcare. 2012;10:117-25. [PMID: 22672601]

20. Upton D, Upton P. Knowledge and use of evidence-based practice by allied health and health science professionals in the United Kingdom. Journal of Allied Health. 2006;35(3):127-33. [PMID: 17036666]

21. McEvoy MP, Williams MT, Olds TS. Evidence based practice profiles: differences among allied health professions. BMC Medical Education. 2010;10:69. [PMID: 20937140]

22. Sandelowski, M. Whatever happened to qualitative description? Research in Nursing \& Health. 2000;23(4):334-40. [PMID: 10940958]

23. Krueger RA, Casey MA. Focus groups - A practical guide for applied research. Thousand Oaks: SAGE; 2009.

24. The Ministry of Education and Cultural Affairs. The Act Concerning the Ethical Review of Research Involving Humans. The Ministry of Education and Cultural Affairs, Stockholm; 2003

25. Krippendorf K. Content Analysis: an Introduction to its Methodology. Thousand Oaks: Sage; 2004.

26. Manderbacka K, Lundberg O. Examining points of reference of self-rated health among Swedish oldest old. Arch Gerontol Geriatr. 1996;23(1):47-60. [PMID: 15374166]

27. Taylor MC. Evidence-based Practice for Occupational Therapists. Oxford: Blackwell Publishing; 2007.

28. Menon A, Korner-Bitensky N, Kastner M, McKibbon KA, Straus S. Strategies for rehabilitation professionals to move evidencebased knowledge into practice: a systematic review. Journal of Rehabilitation Medicine. 2009;41(13):1024-32. [PMID: 19893996]

29. Lizarondo L, Grimmer-Somers K, Kumar S. A systematic review of the individual determinants of research evidence use in allied health. Journal of Multidisciplinary Healthcare. 2011;4:261-72. [PMID: 21847348]

30. Scott SD, Albrecht L, O'Leary K, Ball GDC, Hartling L, et al. Systematic review of knowledge translation strategies in the allied health professions. Implementation Science. 2012;7:70. [PMID: 22831550]

31. Scurlock-Evans L, Upton P, Upton D. Evidence-based practice in physiotherapy: a systematic review of barriers, enablers and interventions. Physiotherapy. 2014;100(3):208-19. [PMID: 24780633]

32. Williams $B$, Perillo $S$, Brown $T$. What are the factors of organisational culture in health care settings that act as barriers to the implementation of evidence-based practice? A scoping review. Nurse Education Today. 2015:35(2);e34-41. [PMID: 25482849]

33. Swedish National Board of Health and Welfare. Kompetensbeskrivningar för Arbetsterapeuter [Descriptions of Competence for Occupational therapists]. Stockholm: Swedish Association of Occupational Therapists; 2015

34. Swedish National Board of Health and Welfare. Kompetensbeskrivningar för Sjukgymnaster [Descriptions of Competence for Physiotherapists]. Stockholm: Swedish National Board of Health and Welfare; 1999

35. Jewell DV, Moore JD, Goldstein MS. Delivering the Physical Therapy Value Proposition: A Call to Action. Physical Therapy. 2012;93(1):104-14. [PMID: 23001526]

36. Burke JP, Gitlin LN. How do we change practice when we have the evidence? The American Journal of Occupational Therapy. 2012;66(5):e85-8. [PMID: 22917134]

37. Kamwendo K. What do Swedish physiotherapists feel about research? A survey of perceptions, attitudes, intentions and engagement. Physiotherapy Research International. 2002;7(1):23-34. [PMID: 11992982]

38. Döpp CME, Steultjens EMJ, Radel J. A Survey of Evidence-Based Practise among Dutch Occupational Therapists. Occupational Therapy International. 2012;19(1):17-27. [PMID: 22468272]

39. Benevides TW, Vause-Earland T, Walsh R. Impact of a Curricular Change on Perceived Knowledge, Skills, and Use of Evidence in Occupational Therapy Practice: A Cohort Study. American Journal of Occupational Therapy. 2015;69 Suppl 2:69. [PMID: 26539674]

40. Rappolt S, Tassone M. How rehabilitation therapists gather, evaluate, and implement new knowledge. The Journal of

(C) The Internet Journal of Allied Health Sciences and Practice, 2016 
Continuing Education in the Health Professions. 2002;22(3):170-80. [PMID: 12227239]

41. Green LA, Gorenflo DW, Wyszewianski L. Validating an instrument for selecting interventions to change physician practice patterns: a Michigan Consortium for Family Practice Research study. The Journal of Family Practice. 2002;51:938-42.

42. Watson PC. On the failure to eliminate hypotheses in a conceptual task. Quarterly Journal of Experimental Psychology. 1960;12:129-40. 